\title{
Terapia manual para o controle da dor cervical em pacientes com migrânea crônica
}

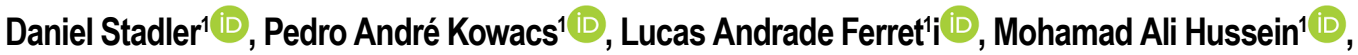 \\ Paulo Sergio Faro Santos ${ }^{2}$, Elcio Juliato Piovesan ${ }^{1}$
}

'Hospital de Clínicas, Universidade Federal do Paraná, Curitiba, Paraná, Brasil.

${ }^{2}$ Instituto de Neurologia e Cardiologia de Curitiba, Setor de Cefaleia e Dor Orofacial, Curitiba, Paraná, Brasil.

\author{
Introdução \\ Migrânea é uma doença com alta prevalência entre a população. É altamente incapacitante, periódica e acomete \\ várias gerações em uma mesma família. Além das dores de cabeça, são prevalentes dores na região do pescoço, \\ bem como os pontos-gatilho associados.
}

\section{Objetivo}

Tratar os indivíduos com diagnóstico de migrânea crônica acometidos de cervicalgia, através da técnica de liberação miofascial Fascial Manipulation (FM). Verificar a possibilidade em diminuir a frequência, duração e intensidade de dores de cabeça após a realização da terapia manual e a quantidade de consumo de analgésico após o tratamento.

\begin{abstract}
Método
Estudo natural em ensaio clínico experimental, analíico - projeto piloto ( $n-36)$ em abordagem terapêutica no tratamento intervencionista da (FM) em participantes da pesquisa com migrânea crônica e sintomas de dores cervicais associadas há pelo menos seis meses, randomizado, com três grupos (grupo tratamento com a técnica mais medicação preventiva, grupo massagem placebo mais medicação preventiva e grupo controle somente medicação preventiva). Optou-se pela padronização dos medicamentos. Deverão usar, os elegidos, o fármaco succinato de sumatriptana mais naproxeno sódico, com a apresentação de $50 \mathrm{mg}$ de sumatriptana (base) e $500 \mathrm{mg}$ de naproxeno sódico e o topiramato com dose de ascensão, única e diária de $25 \mathrm{mg}$ inicialmente, elevando-se para $100 \mathrm{mg}$ em duas doses dia, ou maior dose tolerável. Longitudinal com avaliação independente e reavaliações com algometria. A inclusão é através do diagnóstico dado pelo neurologista, que selecionam voluntários conforme a classificação internacional das cefaleias da IHS 2018. Os desfechos primários serão reduzir as dores de cabeça através da diminuição da percepção da intensidade, frequência e duração da dor pelo diário de cefaleia, ficha (VAS) e ficha de controle de fármacos. Redução das dores cervicais miofasciais, pelo questionário Brasil-nbq e algometria de músculos e nervos por algômetro digital sueco Somedic Sales AB. Melhora na qualidade de vida pelo questionário Whogol-bref, melhora do impacto na incapacidade pela migrânea pelo questionário MIDAS. Melhora do apertamento dentário (bruxismo noturno e diurno) por inventário. Melhora das amplitudes de movimentos (ADM's) das articulações altas da coluna cervical, constatado pela avaliação de fleximetria (flexion rotation test).
\end{abstract}

\section{Resultados e Conclusões}

Estudo em andamento até o momento.

Palavras-chave: Migrânea, Técnicas fisioterápicas, Manipulação musculoesquelética. 